\title{
Aortic Valve Neocuspidalization May Be a Viable Alternative to Ross Operation in Pediatric Patients
}

\author{
Angelo Polito $^{1}$ - Sonia B. Albanese ${ }^{3} \cdot$ Enrico Cetrano $^{3} \cdot$ Sara Forcina $^{3} \cdot$ Marianna Cicenia $^{2} \cdot$ Gabriele Rinelli $^{2}$. \\ Adriano Carotti ${ }^{3}$ (i)
}

Received: 28 September 2020 / Accepted: 18 December 2020 / Published online: 4 January 2021

(c) The Author(s), under exclusive licence to Springer Science+Business Media, LLC part of Springer Nature 2021

\begin{abstract}
The aim of the study was to evaluate the medium-term results of aortic valve neocuspidalization according to Ozaki compared to Ross procedure for treatment of isolated aortic valve disease in pediatric age. Thirty-eight consecutive patients with congenital or acquired aortic valve disease underwent either Ozaki $(n=22)$ or Ross $(n=16)$ operation between 01/2015 and 05/2020. The primary outcome was progression of aortic valve disease and aortic ring and root dimension, whereas secondary outcome was freedom from reintervention or death by type of operation. Median age was $12.4(8.8-15.8)$ years and the prevailing lesion was stenosis in 20 cases (52\%) and incompetence in 18 (48\%). One death occurred in the Ross group in the early postoperative period, while there were no deaths in the Ozaki group. Effective treatment of aortic valve stenosis or regurgitation occurred in both groups and remained stable over a median follow-up of 18.2 (5-32) months. In Ozaki group, 3 patients required aortic valve replacement at 4.9, 3.5, and 33 months, respectively. In Ross group, 1 patient required Melody pulmonary valve replacement, whereas none required aortic valve surgery. Finally, significantly higher aortic transvalvular gradient at follow-up was recorded in Ozaki group compared to Ross group. Overall, there was no significant difference in freedom from reoperation or death between the two groups. The medium-term outcome of Ozaki and Ross in pediatric patients is similar, despite an increased tendency of the former to develop aortic transvalvular gradient in the follow-up. Future larger multicenter studies with longer follow-up are warranted to confirm these results.
\end{abstract}

Keywords Aortic valve disease in children · Pediatric aortic valve replacement $\cdot$ Aortic valve neocuspidalization $\cdot$ Pediatric Ross operation

$\begin{array}{ll}\text { Abbreviations } \\ \text { AV } & \text { Aortic valve } \\ \text { AVD } & \text { Aortic valve disease } \\ \text { AV Neo } & \text { Aortic valve neocuspidalization } \\ \text { AVS } & \text { Aortic valve stenosis } \\ \text { AVI } & \text { Aortic valve incompetence } \\ \text { BSA } & \text { Body surface area }\end{array}$

Adriano Carotti

adriano.carotti@opbg.net

1 Pediatric and Neonatal Intensive Care Unit, Department of Pediatrics, Gynecology and Obstetrics, University Hospitals and Faculty of Medicine, University of Geneva, Geneva, Switzerland

2 Department of Pediatric Cardiology, Bambino Gesù Children's Hospital and Research Institute, Rome, Italy

3 Department of Cardiac Surgery, Bambino Gesù Children's Hospital and Research Institute, Piazza S. Onofrio 4, 00165 Rome, Italy

$\begin{array}{ll}\text { INR } & \text { International normalized ratio } \\ \text { IQR } & \text { Interquartile range } \\ \text { PBAV } & \text { Percutaneous balloon aortic valvuloplasty } \\ \text { COVID-19 } & \text { Corona Virus Disease 2019 } \\ \text { NYHA } & \text { New York Heart Association }\end{array}$

\section{Introduction}

The ideal surgical procedure for AVD in children is still debated [1,2]. Although AV repair is theoretically the most appropriate option in pediatric age [3, 4], AV replacement is sometimes necessary. In this latter case, the Ross operation [5] is considered as the gold standard surgical therapy [6], although its long-term complications [7] have prompted the search for alternative solutions [8], such as AV Neo. First described by Ozaki in adult patients [9], AV Neo represents a promising alternative in pediatric patients with a wide spectrum of AVD including AVS, AVI, infective endocarditis, 
prosthetic valve endocarditis, and annulo-aortic ectasia. The rationale of this technique is to preserve the anatomy of the aortic root and the physiological response throughout the whole cardiac cycle including the coordination between aortic valve, annulus, left ventricle, sinuses of Valsalva, and aorta. Moreover, by creating a large cooptation area with the reconstructed pericardial leaflets, it also theoretically ensures valve competence during annular growth and avoids lifelong anticoagulation therapy. In the initial experience with this procedure, Ozaki reported good results in early and midterm follow-up with a satisfactory freedom from reoperation [10]. However, the majority of cases pertained to an adult population and only recently have appeared in the literature reports that include pediatric patients, with still limited follow-up time [11-13].

In order to understand the role of AV Neo (henceforth called Ozaki procedure) as an alternative solution for AV replacement in the pediatric population, we conducted a retrospective study to evaluate the medium-term outcomes of the Ozaki compared to the Ross procedure for the treatment of isolated AVD.

\section{Materials and Methods}

\section{Study Population}

From January 2015 to May 2020, 38 consecutive patients aged $<18$ years with either congenital or acquired isolated AVD underwent surgical treatment at our institution. Twenty-two (58\%) underwent the Ozaki procedure, whereas 16 patients $(42 \%)$ underwent the Ross operation. Neonates and patients with subaortic obstruction were excluded, in order to select a homogeneous patient population with pure AVD not requiring extensive septoplasty (i.e., Ross-Konno operation). The Scientific Board of Bambino Gesù Children's Hospital and Research Institute approved the study and waived the need for informed patient consent.

\section{Surgical Procedures}

The Ross operation was mainly performed in patients with AVS, while the Ozaki operation was implemented according to surgeon's preference, regardless of preponderant anatomic lesion, without any specific age or weight limitation. Three-leaflet AV Neo according to Ozaki was performed using autologous pericardium when available or either glutaraldehyde-(CardioCel, Milton, Australia) or photo-fixed (Photofix, Crylife, Kennesaw, GA, USA) de-cellularized bovine pericardium. The details of the surgical technique used have been previously reported [13].

On the other hand, Ross procedure was carried out by a standard full root technique with coronary reimplantation.
In case of size mismatch between the aortic annulus and the pulmonary annulus with the latter exceeding more than two $2 \mathrm{~mm}$ the former, a small incision of the aortic annulus $(<5 \mathrm{~mm})$ at the level of the inter-coronary commissure was performed to accommodate the oversized autograft. A pulmonary homograft or a heterograft, either valved bovine jugular vein graft (Contegra, Medtronic, Minneapolis, MN, USA) or porcine pulmonic bioprosthesis (Biointegral Surgical, Mississauga, ON, Canada), was used for right ventricular outflow tract reconstruction.

\section{Echocardiography}

A single reviewer independently measured preoperative, postoperative, and follow-up echocardiogram images with a second reviewer analyzing a random sample. The aortic annulus, the aortic root, and the peak and mean gradients across the AV and the vena contracta jet width were measured and indexed to BSA. In particular, AVI, determined by vena contracta, was measured in parasternal long-axis views and categorized according to its indexed value. Aortic annular size was also measured in parasternal long-axis view. Finally, leaflet mobility of neo-AV was observed in parasternal long- and short-axis views, using also 3D imaging where applicable. Categorization of AVS and AVI is shown in Table 1.

\section{Antiplatelet/Anticoagulant Treatment}

Among patients undergoing Ozaki operation, 17 (45\%) were treated with Aspirin postoperatively. Beginning July 2018, a strategy based on an initial anticoagulant therapy with warfarin (target INR: 1.5-2.5) for 3 months, followed by long-term antiplatelet treatment was used in these patients. In one patient, the target INR was raised to 3.5 for temporary blockage of a valve cusp, which resolved spontaneously without sequelae. The first patient undergoing AV Neo and

Table 1 Categorization of aortic stenosis and incompetence

\begin{tabular}{lll}
\hline Degree & $\begin{array}{l}\text { Aortic valve stenosis } \\
\text { (peak gradient, } \\
\mathrm{mmHg} \text { ) }\end{array}$ & $\begin{array}{l}\text { Aortic valve } \\
\text { incompetence } \\
\text { (indexed vena } \\
\text { contracta, } \mathrm{mm} / \\
\mathrm{m}^{2} \text { ) }\end{array}$ \\
\hline None-trivial & $<15$ & $<2$ \\
Mild & $15-25$ & $2-3.9$ \\
Mild-moderate & $26-35$ & - \\
Moderate & $36-49$ & $4-6$ \\
Moderate-severe & $50-59$ & - \\
Severe & $\geq 60$ & 6 \\
\hline
\end{tabular}

From: Baird et al. [12] J Thorac Cardiovasc Surg 
all patients who underwent Ross procedure did not receive neither anticoagulant nor antiplatelet therapy.

\section{Outcome Measures}

The primary outcome was progression of AVD (stenosis and/or incompetence) throughout hospital course and at follow-up and progression of aortic ring and root dimension at follow-up. The secondary outcome was represented by freedom from reintervention or death.

\section{Statistical Analysis}

Continuous and categorical variables were reported as median (IQR) and number (percentage), respectively. Between-group differences were compared using two-sample $t$-tests and Wilcoxon rank sum tests. Within-group differences were compared using one-sample $t$-tests and Wilcoxon signed rank tests to explore whether changes in echocardiographic scores (e.g., preoperative vs. postoperative, postoperative vs. last follow-up) differed from zero. Rates of freedom from reintervention or death were estimated using Kaplan-Meier methodology. The level for statistical significance was set at $p<0.05$. All analyses were performed using Stata data analysis and statistical software version 11.1 (StataCorp, College Station, TX).

\section{Results}

\section{Demographics}

Pre- and intraoperative characteristics of the entire cohort and by type of operation are summarized in Table 2. Median age and weight at operation of the entire cohort were 12.4 (8.8-15.8) years and 45 (26.5-66) $\mathrm{kg}$, respectively, and the prevailing valve defect was AVS in 20 cases (52\%) and AVI in 18 (48\%). Functional classification of prevalent AVI [14] was type II in 8 cases (44.4\%) and type III in 10 (55.6\%). Six (15\%) patients had tricuspid, 21 (55\%) had bicuspid, and $7(18 \%)$ had unicusp aortic valves; 4 (12\%) patients had structural degeneration of bioprosthetic $(2,6 \%)$ or homograft $(1,3 \%)$ or Ozaki valve $(1,3 \%)$. Congenital lesions accounted for the majority $(28,78.9 \%)$ of the pathology and were associated with genetic syndromes in $7.9 \%$ of cases (Turner, 2 cases, Alagille, 1 case). Twelve patients (31\%) had 14 previous surgeries; 3 (9\%) underwent previous PBAV, whereas 7 (18\%) had 9 previous isolated PBAV. For the Ozaki procedure, autologous or bovine pericardium was used in 13 (59\%) and 9 (41\%) patients, respectively, as already reported [13]. One patient had bilateral enlargement of the aortic valve ring according to a modified Yamaguchi approach [15]. For the Ross procedure, extreme attention was paid to maintaining appropriate matching between aortic ring [19.5 $(15.5-21.5) \mathrm{mm}]$ and autograft size [21(16.5-22) $\mathrm{mm}$ )]. Two patients received a small incision of the aortic annulus to accommodate an oversized autograft. Two patients with adult body surface area $\left(1.9 \mathrm{~m}^{2}\right)$ received autograft external support with woven double velour collagen impregnated polyester graft prosthesis (Hemashield, Getinge AB, Göteborg, Sweden); in one case, the external support was extended to the aortic arch for anterior hemiarch reconstruction.

\section{Early Results}

Median hospital stay was 8 (7-11) days for patients undergoing Ozaki procedure. One patient required drainage of a pericardial serous effusion on postoperative day 4 , whereas one patient required intense anticoagulation for temporary blockage of a cusp occurred on postoperative day 7 , with subsequent complete recovery of the cusp mobility and valve function. In Ross group, one early death occurred. This was a 17-year-old male previously operated twice for resection of discrete subaortic stenosis and aortic valve reconstruction, with mixed aortic valve lesion and prevalent stenosis, who underwent supported Ross and hemiarch reconstruction. Postoperative course was complicated by prolonged dependency from mechanical ventilation and positive IgM, IgG, and IgA serology for COVID-19. The patient passed away on postoperative day 17 for massive chest bleeding and tamponade. Another 18-year-old male with supported Ross developed postoperative mediastinitis, which was successfully treated on postoperative day 5 with debridement and negative pressure wound therapy. Remaining patients in Ross group had an uncomplicated postoperative course with a median hospital stay of 8 (7-14.5) days.

\section{Follow-Up}

All patients were monitored and followed up prior to discharge with an echocardiogram, repeated periodically every 6 months following surgery. The median follow-up for the whole cohort defined by the last available echocardiogram was 18.2 (5-32) months and was $100 \%$ complete. The median follow-up was significantly longer in Ross group compared to the Ozaki group [38.9 (13.8-52.8) months vs. $11.3(4.7-21)$ months, $p=0.02]$.

\section{Assessment of AVD by Echocardiogram}

There were no differences in terms of pre- and intraoperative characteristics between groups, apart from longer extracorporeal circulatory and cross-clamping time in Ross group (Table 2). Tables 3 and 4 show progression of AVS and AVI in Ozaki and Ross group, respectively. 
Table 2 Pre- and intraoperative characteristics of the entire cohort and by type of operation

\begin{tabular}{|c|c|c|c|c|}
\hline Variables & Ozaki (22) & Ross (16) & All (38) & $p$ value \\
\hline Weight at operation $(\mathrm{kg})$ & $55(34-73)$ & $41.8(22.8-57.5)$ & $45(26.5-66)$ & 0.22 \\
\hline Age at operation (years) & $13.9(9.8-16.2)$ & $11.1(6.6-14)$ & $12.4(8.8-15.8)$ & 0.14 \\
\hline Aortic valve peak gradient $(\mathrm{mmHg})$ & $69(30-85)$ & $70(63-85)$ & $70(55-85)$ & 0.37 \\
\hline Aortic valve mean gradient $(\mathrm{mmHg})$ & $40(20-50)$ & $50(39-60)$ & $44(30-50)$ & 0.1 \\
\hline Vena contracta jet width $(\mathrm{mm})$ & $5.5(0-8)$ & $2.6(1-4.6)$ & $3.6(0-7)$ & 0.25 \\
\hline Indexed vena contracta jet width $\left(\mathrm{mm} / \mathrm{m}^{2}\right)$ & $3.6(0-6.7)$ & $2.2(0.6-4.6)$ & $3.1(0.4 .8)$ & 0.53 \\
\hline Aortic root (mm) & $26.5(23-29)$ & $25.5(21.5-28.5)$ & $26(22-29)$ & 0.39 \\
\hline Aortic root indexed $\left(\mathrm{mm} / \mathrm{m}^{2}\right)$ & $19(15.3-23.9)$ & $18.5(17.4-23.3)$ & $18.7(16-23.3)$ & 0.52 \\
\hline Anulus (mm) & $20.5(18-22)$ & $19.5(15.5-21.5)$ & $20(18-22)$ & 0.15 \\
\hline CPB time (min) & $142(117-172)$ & $186(177-229)$ & $169(133-182)$ & $<0.001$ \\
\hline Cross-clamp time (min) & $103(91-113)$ & $136(129-166)$ & $117(100-136)$ & $<0.001$ \\
\hline Redo intervention, $n(\%)$ & $5(22.7)$ & $7(43.7)$ & $12(32)$ & 0.17 \\
\hline Preoperative valvular disease & & & & 0.3 \\
\hline Prevalent AVS, $n(\%)$ & $10(45)$ & $10(62.5)$ & $20(52)$ & \\
\hline Prevalent AVI, $n(\%)$ & $12(55)$ & $6(37.5)$ & $18(48)$ & \\
\hline \multicolumn{5}{|l|}{ Functional classification of prevalent AVI [14] } \\
\hline Type I, $n(\%)$ & $0(0)$ & $0(0)$ & $0(0)$ & \\
\hline Type II, $n(\%)$ & $5(41.7)$ & $3(50)$ & $8(44.4)$ & \\
\hline Type III, $n(\%)$ & $7(58.3)$ & $3(50)$ & $10(55.6)$ & \\
\hline \multicolumn{5}{|l|}{ Diagnosis } \\
\hline Congenital aortic valve disease, $n(\%)$ & $15(68.2)$ & $13(81.2)$ & $28(73.7)$ & \\
\hline Previous repair of doubly-committed VSD, $n(\%)$ & $2(9.1)$ & 0 & $2(5.3)$ & \\
\hline Previous AVR, $n(\%)$ & $1(4.5)$ & $3(18.8)$ & $4(10.5)$ & \\
\hline Rheumatic/endocarditis disease, $n(\%)$ & $418.2)$ & 0 & $4(10.5)$ & \\
\hline Turner & $1(4.5)$ & $1(6.2)$ & $2(5.3)$ & \\
\hline Alagille & $1(4.5)$ & 0 & $1(2.6)$ & \\
\hline \multicolumn{5}{|l|}{ Aortic valve anatomy } \\
\hline Structural degeneration of bioprosthetic valve, $n(\%)$ & $1(4.6)$ & $3(12.5)$ & $4(10.5)$ & \\
\hline Bicuspid aortic valve, $n(\%)$ & $11(50)$ & $10(68.8)$ & $21(55.3)$ & \\
\hline Unicusp aortic valve, $n(\%)$ & $5(22.7)$ & $2(12.5)$ & $7(18.4)$ & \\
\hline Tricuspid aortic valve, $n(\%)$ & $5(22.7)$ & $1(6.2)$ & $6(15.8)$ & \\
\hline \multicolumn{5}{|l|}{ Previous operations } \\
\hline Surgery \pm PBAV, $n(\%)$ & $5(22.8)$ & $7(43.8)$ & 12 (31.6) & \\
\hline Isolated PBAV, $n(\%)$ & $3(13.6)$ & $4(25)$ & $7(18.4)$ & \\
\hline
\end{tabular}

$C P B$ cardiopulmonary bypass, $A V S$ aortic valve stenosis, $A V I$ aortic valve incompetence, $A V R$ aortic valve replacement, $P B A V$ percutaneous balloon aortic valvuloplasty

\section{Aortic Stenosis}

A significant reduction in aortic peak and mean gradients in the postoperative period was obtained in both groups (Fig. 1). In particular, a significant reduction in aortic peak gradient from 69 (30-85) to $12.7(8.4-16.3) \mathrm{mmHg}$ and from 70 (63-85) to $8.5(5.3-15) \mathrm{mmHg}$ for Ozaki and Ross intervention, respectively, was achieved $(p<0.001$ and $p=0.007$, respectively). Similarly, a significant reduction in aortic mean gradient from $40(20-50)$ to $6.9(4.4-10.3)$ $\mathrm{mmHg}$ and from 50 (39-60) to 4.5 (3-8.2) $\mathrm{mmHg}$ for Ozaki and Ross intervention, respectively, was observed
( $p<0.001$ for both comparisons). Compared to the postoperative period, aortic peak and mean gradients at followup showed an upward and downward trend in Ozaki [19 (15.3-30) and $11(8.5-15) \mathrm{mmHg}$ ] and Ross group [5.6 (4.2-8.8) and $2.9(2.4-4.9) \mathrm{mmHg}$ ], respectively.

The aortic mean and peak gradients between the two groups were not different in the immediate postoperative period $(p=0.14)$. Nonetheless, patients who underwent the Ozaki intervention had a significantly higher aortic peak and mean gradients at follow-up compared to patients in the Ross group ( $p<0.001$ for both comparisons). 
Table 3 Progression of aortic stenosis, aortic regurgitation, aortic ring, and aortic root diameter preoperatively, immediately postoperative, and at follow-up (Ozaki operation)

\begin{tabular}{|c|c|c|c|c|c|c|}
\hline Variables & Preoperative & Postoperative & Follow-up & $p$ value* & $p$ value $^{\#}$ & $p$ value $\mathrm{e}^{\S}$ \\
\hline Aortic valve peak gradient $(\mathrm{mmHg})$ & $69(30-85)$ & $12.7(8.4-16.3)$ & $19(15.3-30)$ & $<0.001$ & 0.07 & - \\
\hline Aortic valve mean gradient $(\mathrm{mmHg})$ & $40(20-50)$ & $6.9(4.4-10.3)$ & $11(8.5-15)$ & $<0.001$ & 0.04 & - \\
\hline Vena contracta jet width $(\mathrm{mm})$ & $5.5(0-8)$ & $0(0-1.5)$ & $1.8(0-2.8)$ & $<0.001$ & 0.03 & - \\
\hline Indexed vena contracta jet width $\left(\mathrm{mm} / \mathrm{m}^{2}\right)$ & $3.6(0-6.7)$ & $0(0-1.1)$ & $1.1(0-2.3)$ & $<0.001$ & 0.03 & - \\
\hline Aortic root (mm) & $26.5(23-29)$ & - & $27(23-31)$ & - & - & 0.03 \\
\hline Aortic root indexed $\left(\mathrm{mm} / \mathrm{m}^{2}\right)$ & $19(15.3-23.9)$ & - & $17.3(15-23)$ & - & - & 0.94 \\
\hline Aortic ring $(\mathrm{mm})$ & $20.5(18-22)$ & - & $19(17-22)$ & - & - & 0.15 \\
\hline Aortic ring indexed $\left(\mathrm{mm} / \mathrm{m}^{2}\right)$ & $14.2(12.2-18.3)$ & - & $12.2(11.4-16.2)$ & - & - & 0.08 \\
\hline
\end{tabular}

* $p$ for comparison between preoperative and immediately postoperative period

\# $p$ for comparison between the immediately postoperative period and follow-up

${ }^{\S} p$ for comparison between the preoperative period and follow-up

Table 4 Progression of aortic stenosis, aortic regurgitation, aortic ring, and aortic root diameter preoperatively, immediately postoperative, and at follow-up (Ross operation)

\begin{tabular}{|c|c|c|c|c|c|c|}
\hline Variables & Preoperative & Postoperative & Follow-up & $p$ value* & $p$ value $^{\#}$ & $p$ value $^{\S}$ \\
\hline Aortic valve peak gradient $(\mathrm{mmHg})$ & $70(63-85)$ & $8.5(5.3-15)$ & $5.6(4.2-8.8)$ & 0.007 & 0.03 & - \\
\hline Aortic valve mean gradient $(\mathrm{mmHg})$ & $50(39-60)$ & $4.5(3-8.2)$ & $2.9(2.4-4.9)$ & $<0.001$ & 0.03 & - \\
\hline Vena contracta jet width $(\mathrm{mm})$ & $2.6(0.9-4.6)$ & $1.4(0-1.8)$ & $1.7(0.9-2.3)$ & 0.006 & 0.12 & - \\
\hline Indexed vena contracta jet width $\left(\mathrm{mm} / \mathrm{m}^{2}\right)$ & $2.2(0.6-4.6)$ & $0.9(0-1.5)$ & $1.2(0.5-2)$ & 0.005 & 0.31 & - \\
\hline Aortic root (mm) & $25.5(21.5-28.5)$ & - & $30(24.5-37)$ & - & - & 0.009 \\
\hline Aortic root indexed $\left(\mathrm{mm} / \mathrm{m}^{2}\right)$ & $18.5(17.5-23.3)$ & - & $22(18.8-24.2)$ & - & - & 0.19 \\
\hline Aortic ring $(\mathrm{mm})$ & $19.5(15.5-21.5)$ & - & $21(19-25.5)$ & - & - & 0.003 \\
\hline Aortic ring indexed $\left(\mathrm{mm} / \mathrm{m}^{2}\right)$ & $15.5(12.6-20.6)$ & - & $13.7(12.8-19.3)$ & - & - & 0.71 \\
\hline
\end{tabular}

* $p$ for comparison between preoperative and immediately postoperative period

\# $p$ for comparison between the immediately postoperative period and follow-up

${ }^{\S} p$ for comparison between the preoperative period and follow-up

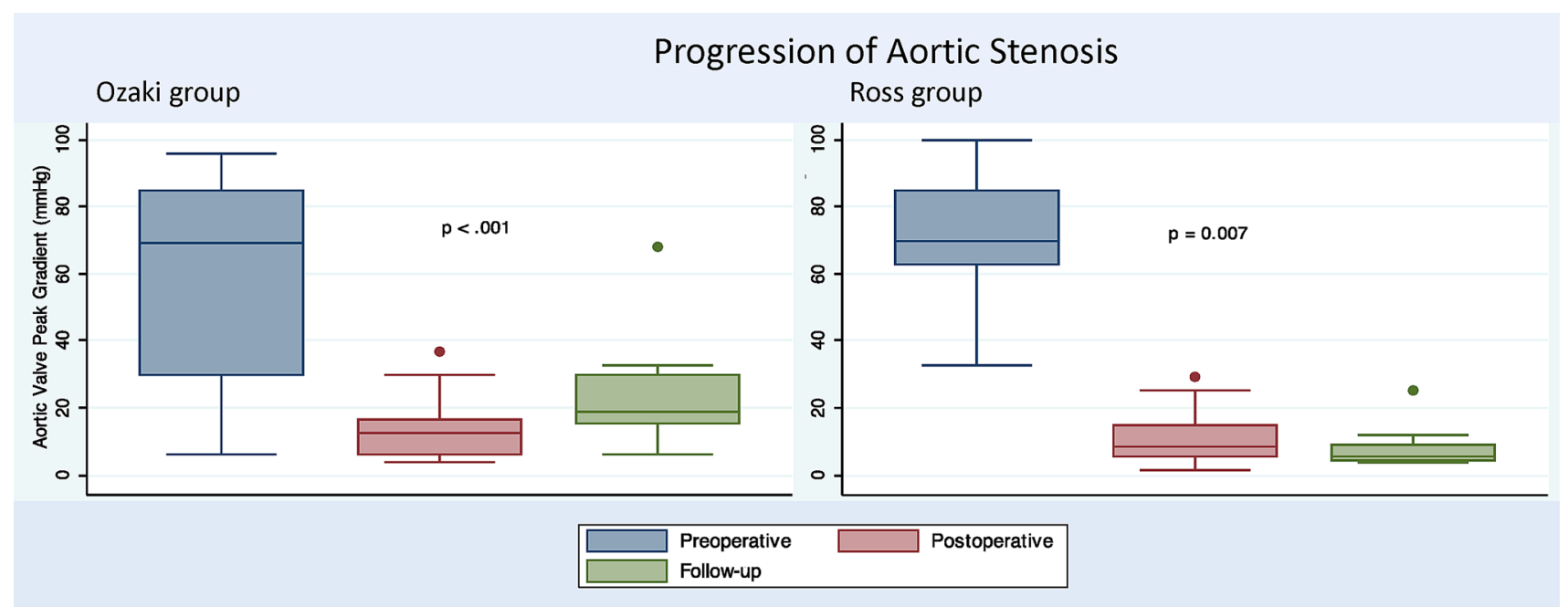

Fig. 1 Progression of aortic valve stenosis in Ozaki and Ross group 


\section{Aortic Regurgitation}

The indexed vena contracta jet width in the postoperative period significantly decreased from $3.6(0-6.7)$ to 0 $(0-1.5) \mathrm{mm} / \mathrm{m}^{2}$ for Ozaki group and from $2.2(0.6-4.6)$ to $0.9(0-1.5) \mathrm{mm} / \mathrm{m}^{2}$ for Ross group $(p<0.001$ and $p=0.005$, respectively) (Fig. 2). Compared to the postoperative period, the median indexed vena contracta jet widths at follow-up showed an upward trend in both groups $[1.1(0-2.3) \mathrm{mm} /$ $\mathrm{m}^{2}$ in Ozaki group and $1.2(0.5-2) \mathrm{mm} / \mathrm{m}^{2}$ in Ross group, respectively]. Furthermore, no significant differences were found in the indexed vena contracta jet width in the postoperative period and at follow-up between the two groups.

\section{Assessment of Aortic Ring and Root Dimension by Echocardiogram}

Tables 3 and 4 show progression of aortic ring and aortic root diameter in Ozaki and Ross group, respectively. The comparison of the long-axis view measurements of the aortic annulus at the last echocardiogram with respect to the preoperative ones showed a non-significant decrease [20.5 (18-22) vs. 19 $(17-22) \mathrm{mm}(p=0.15)]$ in Ozaki group, while a significant increase [19.5 (15.5-21.5) vs. $21(19-25.5) \mathrm{mm}(p=0.003)]$ at follow-up was recorded in Ross group. Indexed measurements of the aortic annulus, however, did not confirm such result. On the other hand, significant aortic root dilatation at follow-up compared to the preoperative period was observed for both groups particularly in Ross patients by comparing absolute values of preoperative and follow-up measurements which increased from $26.5(23-29)$ to $27(23-31) \mathrm{mm}(p=0.03)$ in Ozaki group and from $25.5(21.5-28.5)$ to $30(24.5-37) \mathrm{mm}$ $(p=0.009)$ in Ross group. Those results were not confirmed when indexed aortic root diameter was analyzed.

\section{Survival/Reoperations}

One patient in Ross group died in the early postoperative period. Two $(9.1 \%)$ of the initial patients who underwent the Ozaki procedure required early conversion to valve replacement. The first was an 8-year-old boy with stenotic bicuspid $\mathrm{AV}$, who developed intermittent myocardial ischemia due to redundancy of the left coronary cusp obstructing the left coronary ostium. The patient was successfully converted to a Ross procedure 4.9 months after Ozaki operation and was therefore subsequently included in the Ross series of this study. The second patient was a 17 -year-old young boy who had already undergone combined mitral and AV repair for rheumatic disease who subsequently underwent the Ozaki procedure as a rescue treatment after a failed attempt of mechanical AV replacement. This patient experienced an aseptic aortic root disruption 3.5 months after surgery, was then successfully converted to homograft aortic root replacement, and was in NYHA class I 30 months postoperatively.

A third patient in the Ozaki group, a 9.5-year-old child with repaired truncus arteriosus, previous AV repair, previous AV replacement with bioprosthesis, and previous Ozaki operation (first patient of our series) developed severe stenosis 33 months postoperatively and required mechanical AV replacement. Of note is the fact that the child was not receiving any anticoagulant or antiplatelet therapy. At operation, all three cusps originally made with heterologous pericardium (Cardiocel@) appeared uniformly severely calcified. Interestingly, the aortic ring diameter at reoperation was $2 \mathrm{~mm}$ larger than previously measured at the time of the Ozaki procedure. This child is in NYHA class I 14 months after the procedure. Finally, one patient completed a regular pregnancy giving birth to a healthy baby by cesarean section 28 months after Ozaki procedure. Antiplatelet therapy

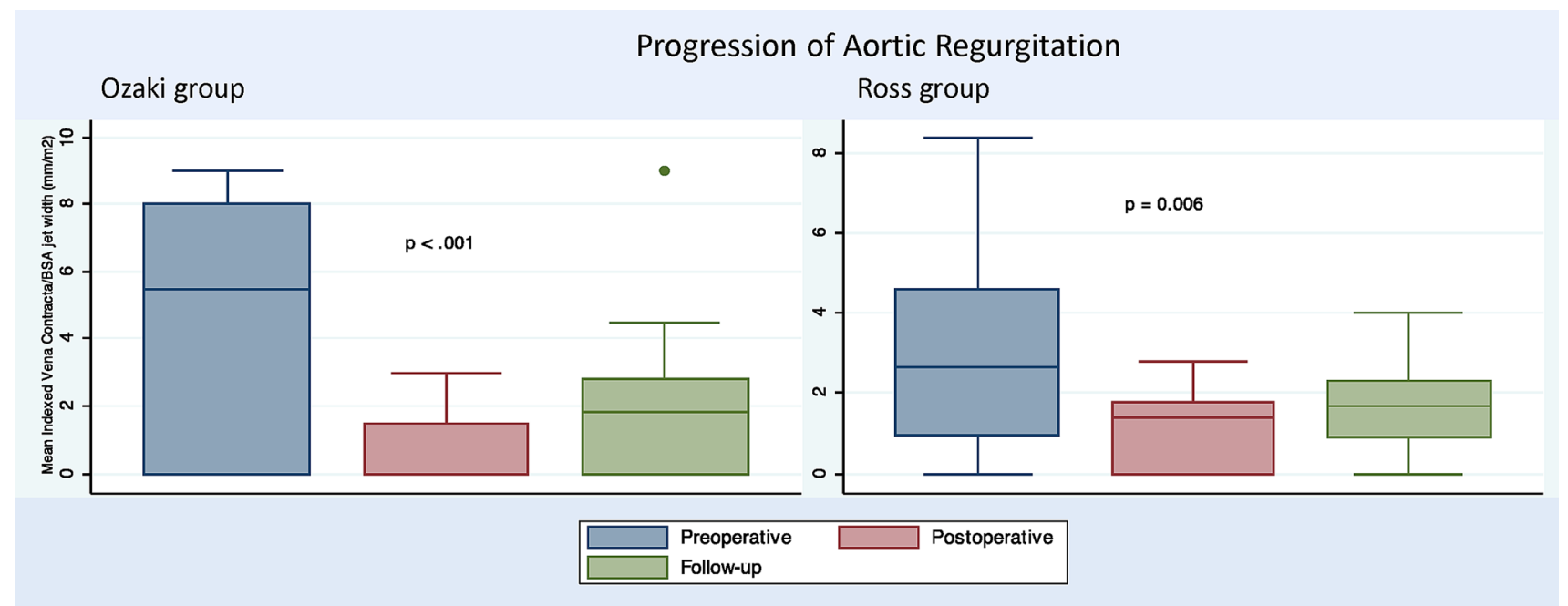

Fig. 2 Progression of aortic valve regurgitation in Ozaki and Ross group 
was discontinued throughout the gestational period. No changes in valve function occurred during pregnancy.

At the time of the writing of this article, 4 (25\%) patients are monitored for moderate homograft valve incompetence and 1 for moderate stenosis in the Ross group. One 15-yearold boy with severe homograft valve incompetence underwent Melody pulmonary valve replacement 57 months postoperatively. To date, none of patients in Ross group required any intervention either on the aortic valve or on the aortic root. No episode of endocarditis was detected in either group.

Finally, freedom from reintervention or death at 24 months was 89.4\% (64-97) and 93.5\% (63-99) in Ozaki and Ross group, respectively ( $p=0.2$, Fig. 3 ).

\section{Comment}

Although AV repair is theoretically the most appropriate option in pediatric age [3, 4], AV replacement is sometimes necessary. In this latter case, the Ross operation is considered as the gold standard technique. However, Ross operation is burdened with significant operative mortality $[1,2,5,6,16$, 17] and late complications related to autograft dilatation and durability of both autograft and pulmonary conduit $[7,8,18]$. Therefore, alternative pathways such as AV Neo according to Ozaki have recently been explored in pediatric patients. Despite the limited follow-up period, Ozaki operation appears to represent a viable alternative solution for $\mathrm{AV}$ replacement in children [11, 12], as also reported by our group [13]. In particular, the data analysis of this study suggests that the Ozaki procedure represents a safe alternative to Ross operation in children. Both interventions showed satisfactory comparable early- and midterm hemodynamic results. Aortic ring and root indexed dimensions remained stable throughout the study period in both groups. As previously shown [18], when

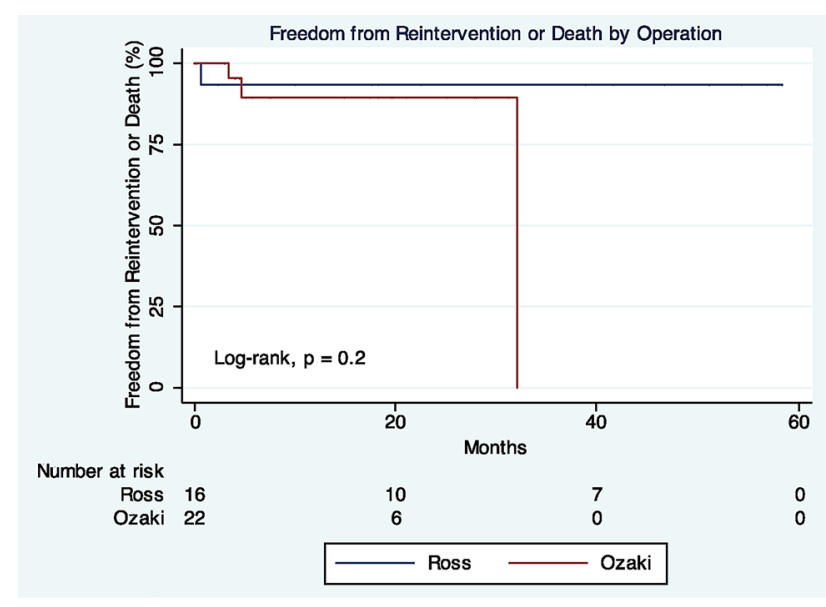

Fig. 3 Freedom from reintervention or death by type of operation absolute measures were compared, significant dilation of both aortic ring and root occurred in the Ross group.

A significant reduction in both the aortic peak and mean gradients in the postoperative period after both procedures suggests adequate resolution of AV stenotic disease. However, an upward trend of those parameters at follow-up, compared to the postoperative period, was found in the Ozaki group. As previously reported [13], such increase is probably related to the lack of growth of the aortic ring over time. Our findings are in contrast with Baird et al. who showed significant growth of the aortic ring at follow-up in all patients treated according to Ozaki, primarily in those who received aortic annular enlargement [12]. A lower percentage of annular enlargement performed in our series ( $4.5 \%$ vs. the $14 \%$ compared to Baird [12]) as well as the use of a different echocardiographic approach for the measurement of the aortic annulus (long-axis and short-axis views in Baird's study vs. exclusive long-axis view in our series) might account for this contradiction. Nevertheless, such differences in aortic transvalvular gradients at follow-up did not translate into a significant difference in terms of death or morbidity between the two techniques.

Despite a longer follow-up period in the Ross group, the trend for reoperations was more favorable in patients who underwent the Ross operation than in the Ozaki group. Nonetheless, this difference might be explained by the inherent problem of the sometimes long and steep learning curve associated with a new surgical technique. In fact, while Ross operation was a consolidated practice at our institution, Ozaki operation was introduced during the study period.

Compared to the immediate postoperative period, aortic peak and mean gradients as well as vena contracta jet width and indexed vena contracta jet width at follow-up showed an upward trend in patients who underwent the Ozaki procedure. Although this does not appear to have produced a significantly relevant clinical impact in this group, questions regarding the durability of the Ozaki surgical strategy can reasonably be asked. Further studies characterized by longer follow-up periods are needed to answer these questions.

This study has limitations. First of all, this is a singlecenter retrospective study with a limited sample size. Secondly, while Ross operation was mainly performed in patients with AVS, indication to Ozaki procedure was left to surgeon preference both in terms of preponderant anatomic lesion and age/weight category. The limited followup time precludes any definitive conclusion regarding the comparison between the two surgical techniques in exams. The median duration of follow-up was inconsistent between the two groups and this might affect data analysis. The analysis of aortic root dilatation at follow-up might have been overestimated in the Ozaki group, due to bilateral enlargement of the aortic annulus performed in one patient and underestimated in the Ross group, due to external graft support of the autograft performed in two patients. 
This study has also strengths. This is the first study exploring the direct comparison of the Ozaki and Ross techniques in a population of pediatric patients with pure congenital or acquired AVD.

Despite a well-established surgical technique, Ross operation might not be the best approach for AV replacement in children. Though decisive conclusions cannot be drawn, our data suggest that Ross and Ozaki interventions might have comparable midterm results in terms of AVD progression in pediatric patients with complex isolated AVD. According to our experience, the Ozaki technique represents a less invasive and probably a more suitable strategy even for smaller patients. The potential need for reintervention of patients after Ozaki procedure should be weighed against that for autograft reoperation after Ross. As the Ozaki intervention does not preclude the use of future surgical solutions, we believe that an integrated approach based on the early use of the Ozaki procedure as a bridging solution towards subsequent alternative surgical treatments of AVD might represent a viable strategy. Future larger multicenter studies with longer follow-up are warranted to confirm these results.

Author Contributions All authors contributed to the study conception and design. AP and MC involved in data curation and investigation. SBA and GR did supervision and validation. EC did investigation. SF involved in data collection. AC participated in writing - original draft and writing-review \& editing.

Funding None.

Data Availability Not applicable.

Code Availability Not applicable.

\section{Compliance with Ethical Standards}

Conflict of interest The authors declare that they have no conflicts of interest.

Ethical Approval This is an observational study. The Research Ethics Committee of Bambino Gesù Children's Hospital and Research Institute has confirmed that no ethical approval is required.

Consent to Participate The Scientific Board of Bambino Gesù Children's Hospital and Research Institute has approved the study and has waived the need for informed patient consent.

Consent for Publication The Scientific Board of Bambino Gesù Children's Hospital and Research Institute has approved the study and has waived the need for informed patient consent.

\section{References}

1. Akins CW, Miller DC, Turina MI, Kouchoukos NT, Blackstone $\mathrm{EH}$, Grunkemeier GL et al (2008) Guidelines for reporting mortality and morbidity after cardiac valve interventions. Ann Thorac Surg 85:1490-1495

2. Sharabiani MTA, Dorobantu DM, Mahani AS, Turner M, Tometzki AJP, Angelini GD et al (2016) Aortic valve replacement and the Ross operation in children and young adults. J Am Coll Cardiol 67:2858-2870

3. d'Udekem Y (2011) Aortic valve surgery in children. Heart 97:1182-1189

4. Baird CW, Myers PO, del Nido PJ (2012) Aortic valve reconstruction in the young infants and children. Semin Thorac Cardiovasc Surg Pediatr Card Surg Annu 15:9-19

5. Ross DN (1967) Replacement of aortic and mitral valves with a pulmonary autograft. Lancet 2:956-958

6. Takkenberg JJM, Kappetein AP, Van HLA, Witsenburg M, Van O-G, Bogers JJC (2005) Pediatric autograft aortic root replacement: a prospective follow-up study. Ann Thorac Surg 80:1628-1633

7. Luciani GB, Lucchese G, Carotti A, Brancaccio G, Abbruzzese P, Caianiello G et al (2014) Two decades of experience with the Ross operation in neonates, infants and children from the Italian Paediatric Ross Registry. Heart 100:1954-1959

8. Etnel JRG, Elmont LC, Ertekin E, Mokhles MM, Heuvelman HJ, Roos-Hesselink JW et al (2016) Outcome after aortic valve replacement in children: a systematic review and meta-analysis. J Thorac Cardiovasc Surg 151:143-152

9. Ozaki S, Kawase I, Yamashita H, Uchida S, Nozawa Y, Matsuyama $\mathrm{T}$ et al (2011) Aortic valve reconstruction using selfdeveloped aortic valve plasty system in aortic valve disease. Interact Cardiovasc Thorac Surg 12:550-553

10. Ozaki S, Kawase I, Yamashita H, Uchida S, Takatoh M, Kiyohara N (2018) Midterm outcomes after aortic valve neocuspidization with glutaraldehyde-treated autologous pericardium. J Thorac Cardiovasc Surg 155:2379-2387

11. Wiggins LM, Mimic B, Issitt R, Ilic S, Bonello B, Marek J, Kostolny M (2020) The utility of aortic valve leaflet reconstruction techniques in children and young adults. J Thorac Cardiovasc Surg 159:2369-2378

12. Baird CW, Sefton B, Chávez M, Sleeper LA, Marx GR, del Nido PJ (2020) Congenital aortic and truncal valve reconstruction utilizing the Ozaki technique: short-term clinical results. J Thorac Cardiovasc Surg. https://doi.org/10.1016/j.jtcvs.2020.01.087

13. Polito A, Albanese SB, Cetrano E, Cicenia M, Rinelli G, Carotti A (2020) Aortic valve neocuspidalization in pediatric patients with isolated aortic valve disease: early experience. Interact Cardiovasc Thorac Surg. https://doi.org/10.1093/icvts/ivaa237

14. El Khoury G, Glineur D, Rubay J, Verhelst R, d'Udekem d'Acoz Y, Poncelet A et al (2005) Functional classification of aortic root/valve abnormalities and their correlation with etiologies and surgical procedures. Curr Opin Cardiol 20:115-121

15. Yamaguchi M, Ohashi H, Imai M, Oshima Y, Hosokawa Y (1991) Bilateral enlargement of the aortic valve ring for valve replacement in children. J Thorac Cardiovasc Surg 102:202-206

16. Brancaccio G, Polito A, Hoxha S, Giannico S, Amodeo A, Carotti A (2014) The Ross procedure in patients aged less than 18 years: the midterm results. J Thorac Cardiovasc Surg 147:383-388

17. Elkins RC, Thompson DM, Lane MM, Elkins CC, Peyton MD (2008) Ross operation: 16-year experience. J Thorac Cardiovasc Surg 136:623-630

18. Hörer J, Kasnar-Samprec J, Charitos E, Stierle U, Bogers AJ, Hemmer W et al (2013) Patient age at the Ross operation in children influences aortic root dimensions and aortic regurgitation. World J Pediatr Congenit Heart Surg 4:245-252

Publisher's Note Springer Nature remains neutral with regard to jurisdictional claims in published maps and institutional affiliations. 